\title{
The Role of Radiation in Accelerating Tropical Cyclogenesis in Idealized Simulations
}

\author{
WARREN P. SMITH \\ Cooperative Institute for Research in Environmental Sciences, Department of Atmospheric and Oceanic Sciences, \\ University of Colorado Boulder, and Atmospheric Chemistry Observations and Modeling Laboratory, \\ National Center for Atmospheric Research, Boulder, Colorado \\ Melville E. Nicholls ANd Roger A. Pielke SR. \\ Cooperative Institute for Research in Environmental Sciences, Department of Atmospheric and Oceanic Sciences, \\ University of Colorado Boulder, Boulder, Colorado
}

(Manuscript received 21 February 2019, in final form 25 January 2020)

\begin{abstract}
Recent numerical modeling studies indicate the importance of radiation in the transformation from a tropical disturbance to a tropical depression, a process known as tropical cyclogenesis. This paper employs a numerical modeling framework to examine the sensitivity to radiation in idealized simulations for different initial vortex strengths, and in doing so highlights when during tropical cyclogenesis radiation is most important. It is shown that all else being equal, a stronger initial vortex reduces the impact that radiation has on accelerating tropical cyclogenesis. We find that radiation's primary role is to moisten the core of a disturbance through nocturnal differential radiative forcing between the disturbance and its cloud-free surroundings, and after sufficient moistening occurs over a deep layer and the winds are sufficiently strong at the surface, radiation no longer plays as significant a role in tropical cyclogenesis.
\end{abstract}

\section{Introduction}

Hurricanes are devastating storms capable of producing death tolls in the thousands and damage in the tens of billions of U.S. dollars. Prior to hurricane landfall, a vortex must transform from a tropical disturbance into a tropical depression by a process known as tropical cyclogenesis. It has been discovered through numerical modeling that longwave and shortwave radiation (hereafter just "radiation" unless otherwise noted) dramatically accelerates tropical cyclogenesis, but an important question still remains that is addressed in this paper: at what stage of development does radiation play the most significant role? We address this question by performing idealized simulations of tropical cyclogenesis with different initial vortex strengths, which represent different stages of a developing tropical disturbance.

It has long been recognized that a diurnal cycle of tropical convection exists (e.g., Kraus 1963; Fingerhut 1978). Specifically, tropical convective activity peaks in

Corresponding author: Warren P. Smith, wsmith@ucar.edu the early morning and is weakest in the afternoon local time (Jacobson and Gray 1976). This has been attributed to both a nocturnal differential radiative forcing between cloud structures and their relatively clear-sky surroundings (Gray and Jacobson 1977) and to nocturnal longwave-induced destabilization (Xu and Randall 1995). Convective destabilization of clouds due to longwave radiation is sensitive to the cloud quantity (Godbole 1973) and has been linked to the intensification of tropical mesoscale convective systems (Dudhia 1989; Miller and Frank 1993).

Numerical simulations of tropical cyclones (TCs) demonstrate strong sensitivity to the changes in radiation due to the presence of hydrometeors, also known as cloud radiative forcing (CRF). The inclusion of CRF in a numerical simulation often results in a broader storm circulation and enhances uppertropospheric radial outflow, ascent in the core of the vortex, and outer-core horizontal winds $(\mathrm{Bu}$ et al. 2014). TC tracks, intensities, distribution of winds and strength of the secondary circulation may also be affected by CRF (Fovell et al. 2016). 
Due to the documented diurnal variability of tropical convection and the impacts of CRF on TCs, it follows that TCs also exhibit a diurnal variability in convective activity (e.g., Leppert and Cecil 2016). This signature exists in observations of TCs (e.g., Dunion et al. 2014; Knaff et al. 2019) and has been reproduced in numerical models (e.g., Navarro and Hakim 2016). In addition to convective activity, TCs also exhibit diurnal cycles in their wind fields and their thermodynamic structure (Dunion et al. 2019). Wind speeds tend to peak about $6 \mathrm{~h}$ after the peak in heating occurs (Navarro et al. 2017). The reduction of a TC's radius of maximum winds during intensification is shown to be sensitive to the diurnal cycle of shortwave radiation in the tropics, as demonstrated by daytime- and nighttime-only simulations of Hurricane Edouard (2014) (Tang et al. 2019).

The impacts of radiation on stability in the tropics is an important consideration for TCs as well. While longwave emission may destabilize the atmosphere, shortwave radiation tends to stabilize the atmosphere by diminishing cloud-top cooling (Schmetz and Beniston 1986). This may in turn restrict secondary eyewall formation in mature TCs (Tang et al. 2017). Cooling at the tropopause and above can lead to significant changes in the potential intensity of TCs (e.g., Ramsay 2013; Wang et al. 2014). Temperatures in the upper troposphere have recently been linked to changes in ice species, upper-level vertical mass flux and the height of the TC's upper-tropospheric outflow (Trabing et al. 2019). Radiation's impacts on the Brunt-Väisälä frequency have been linked to potential vorticity near the tropopause, which has implications for the rapid intensification of TCs (Duran and Molinari 2019).

The transformation from a tropical disturbance to a tropical depression, otherwise known as tropical cyclogenesis (TCG) marks the formation of a TC. Some of the earliest work found that TCG is favored in regions with sea surface temperatures (SSTs) in excess of $26^{\circ} \mathrm{C}$ and vertical wind shear less than $10 \mathrm{kt}\left(\sim 5.1 \mathrm{~m} \mathrm{~s}^{-1}\right)$ (Gray 1968). More recently, the roles of convective organization and inner-core moisture in TCG have been explored in the literature. Early in the evolution of a tropical disturbance, the core tends to gradually warm and moisten and angular momentum surfaces are drawn inwards (Kilroy et al. 2017). The character of convection may change once the relative humidity $(\mathrm{RH})$ reaches about $80 \%$ in the disturbance core below a height of $7 \mathrm{~km}$, increasing the likelihood of TCG (Davis 2015). Although midlevel vortices (MLVs) are frequent precursors to TCG (e.g., Ritchie and Holland 1997; Raymond and López
Carrillo 2011; Davis and Ahijevych 2012), they are not necessarily essential for the development of a tropical depression (Kilroy et al. 2018).

Recent numerical modeling studies indicate the paramount importance of radiation in TCG. Removing radiation in a simulation often inhibits TCG from occurring for several days, suggesting that radiation plays a very active role in the development of a tropical disturbance (Nicholls and Montgomery 2013; Melhauser and Zhang 2014; Nicholls 2015; Tang and Zhang 2016). Feedbacks of longwave radiation may assist with the self-aggregation of convection (Muller and Romps 2018) and the development of a circulation (Wing et al. 2016). Although there appear to be distinctly different "pathways" to TCG depending on a model's initialization and chosen physics parameterizations (Hendricks et al. 2004; Montgomery et al. 2006; Nolan 2007), turning off radiation dramatically slows development regardless of the specific mechanism at play, attributed to clear-sky longwave cooling acting on a tropical depression's surrounding environment (Nicholls and Montgomery 2013).

During TCG, sensitivity to radiation appears to be due in large part to a weak nocturnal transverse circulation brought about from differential radiative forcing between the cloudy disturbance and the surrounding cloud-free region at night, similar to the mechanism discussed in Gray and Jacobson (1977) for organized convective clouds. This circulation is associated with a slow rising motion in the core and subsidence in the surroundings, which leads to increased RH in the core of the disturbance and promotes convection (Nicholls 2015). Tao et al. (1996) also noted that large-scale radiative cooling tends to increase the $\mathrm{RH}$ of the core, which enables additional condensation in a convective column. A moist vortex is more likely to undergo TCG (e.g., Bister and Emanuel 1997; Pielke and Pielke 1997; Rappin et al. 2010; Wang 2012), lending further support to the fact that radiation accelerates development. TCG is also sensitive to heating and cooling from the diurnal cycle of radiation, which impacts deep, moist convection (Melhauser and Zhang 2014). The detrimental effects of shortwave radiation on tropical convection also apply to developing tropical disturbances, where sensitivity studies to shortwave radiation indicate that TCG is often delayed with it included (Tang and Zhang 2016).

Despite the documented sensitivity of tropical disturbances to radiation as found in numerical modeling studies, there has been little exploration into the exact "stage" where radiation is the most important during TCG, a gap that this study seeks to address. 
TABLE 1. An overview of the six "core" simulations performed in this study. The two rightmost columns show the maximum azimuthally averaged tangential wind values from the initial vortex at the lowest model level (40.6 m AGL) and at the height of maximum winds (about $4 \mathrm{~km} \mathrm{AGL),} \mathrm{respectively.}$

\begin{tabular}{lcccr}
\hline \multicolumn{1}{c}{ Name } & Radiation & Microphysics & Max surface $V\left(\mathrm{~m} \mathrm{~s}^{-1}\right)$ & Max $V$ at $\left.4 \mathrm{~km}(\mathrm{~m} \mathrm{~s})^{-1}\right)$ \\
\hline RAD_Weak & RRTMG & Thompson & 4.7 & 9.1 \\
NORAD_Weak & - & Thompson & 4.7 & 9.1 \\
RAD_Medium & RRTMG & Thompson & 6.3 & 12.2 \\
NORAD_Medium & - & Thompson & 6.3 & 12.2 \\
RAD_Strong & RRTMG & Thompson & 7.9 & 15.3 \\
NORAD_Strong & - & Thompson & 7.9 & 15.3 \\
\hline
\end{tabular}

Nicholls and Montgomery (2013) ran an extensive suite of simulations varying many initial parameters in their model, one of which was vortex strength. However, none of their simulations without radiation were run for the stronger version of their vortex. Nicholls (2015) briefly explored the impacts of imposing radiative forcing on two vortices that had already undergone TCG and concluded that radiation did not have as large an impact on intensification as it does on genesis, but these experiments did not employ a fullphysics suite, nor were their initial vortices weak enough to make inferences for TCG. Craig (1996) noted in simulations that radiation did not play a significant role in the intensification of TCs, but their initial vortex was a bit too strong to infer any applications for TCG.

The current work performs full-physics idealized simulations of three different initial vortices and explores how the sensitivity to radiation varies among them. In doing so, we highlight the stage of TCG where radiation is most important, giving further insight into our understanding of the role that radiation plays. This provides important guidance for operational forecasting about factoring in the time of day, cloud structure and cyclonic circulation strength when making predictions about the timing of TC formation and intensification. We hypothesize that the stronger a prescribed vortex is in our model, the less impact that radiation has on the timing of TCG.

\section{Methods and approach}

\section{a. Numerical model and experimental design}

The Advanced Research WRF Model (WRF-ARW), version 3.9, is employed for the simulations presented in this study (Skamarock et al. 2008). Our simulations are based on the TC "test" simulation that comes with the default WRF-ARW distribution, which we modify significantly for the objectives in this study. We change the initial vertical structure of horizontal winds so that they are maximized at midlevels rather than the surface, since a midlevel mesoscale convective vortex has been observed by numerous studies to be a precursor to TCG (e.g., Zehr 1992; Harr and Elsberry 1996; Bister and Emanuel 1997; Reasor et al. 2005). This change also allows our initial vortex to conform more closely to the one employed in Nicholls and Montgomery (2013) and Nicholls (2015), who used the Regional Atmospheric Modeling System (RAMS; Pielke et al. 1992). The exact methodology and formula for our vortex is given in appendix A.

The simulations all contain three concentric grids with horizontal grid spacings of $15 \mathrm{~km}(301 \times 301$ points $)$, $3 \mathrm{~km}(301 \times 301$ points $)$ and $1 \mathrm{~km}(400 \times 400$ points $)$. All three grids have 60 vertical levels that are vertically stretched with height from about 100-m spacing near the surface to about $1-\mathrm{km}$ spacing near the tropopause. The lowest model level is at $40.6 \mathrm{~m}$ above ground level (AGL) and the model top is at $25.0 \mathrm{~km}$ AGL. WRF uses a terrain-following $\eta$ vertical coordinate; for each model level we calculate physical height by averaging the base-state geopotential field in $x, y$, and time and then dividing by $g=9.81 \mathrm{~m} \mathrm{~s}^{-2}$. The SST is set to a constant $28^{\circ} \mathrm{C}$ and the Coriolis force is approximated with an $f$ plane at a latitude of $15^{\circ} \mathrm{N}$. The domains are located at $0^{\circ}$ longitude and initialized at midnight local time on 1 September.

These simulations utilize the mean tropical sounding from Jordan (1958) as a horizontally uniform initial state. Physics schemes used in these simulations include the Thompson microphysics scheme (Thompson et al. 2008), the RRTMG longwave and shortwave radiation schemes (Iacono et al. 2008) that update every $5 \mathrm{~min}$, and the YSU planetary boundary layer (PBL) scheme (Hong et al. 2006). The authors do not feel there is a need to parameterize convection in each disturbance's distant surroundings because of the idealized nature of these simulations, so no cumulus scheme is activated for the coarse grid. An implicit gravity wave damping layer (damp_opt $=3$ ) is used to 
(a) Ice Mixing Ratio $(\mathrm{g} / \mathrm{kg}) \mathrm{r}=3.9$

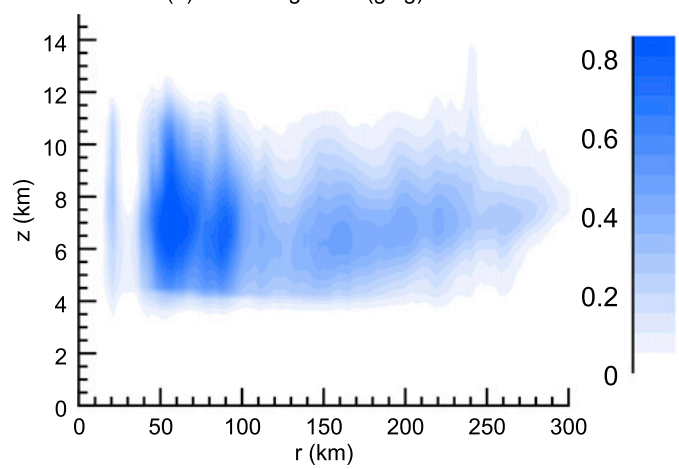

(c) Ice Mixing Ratio (g/kg) Default

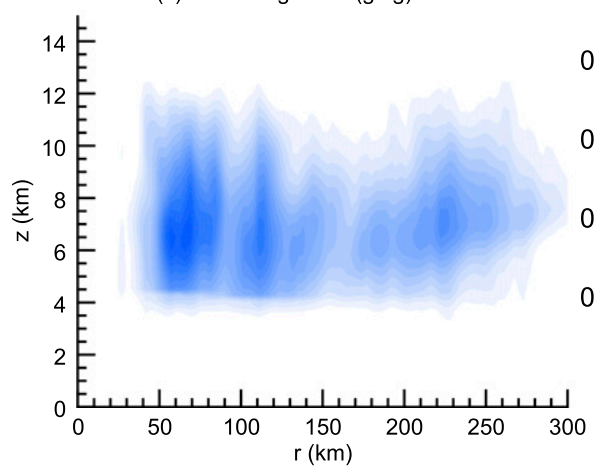

(b) Ice Mixing Ratio ( $\mathrm{g} / \mathrm{kg}$ ) Mean

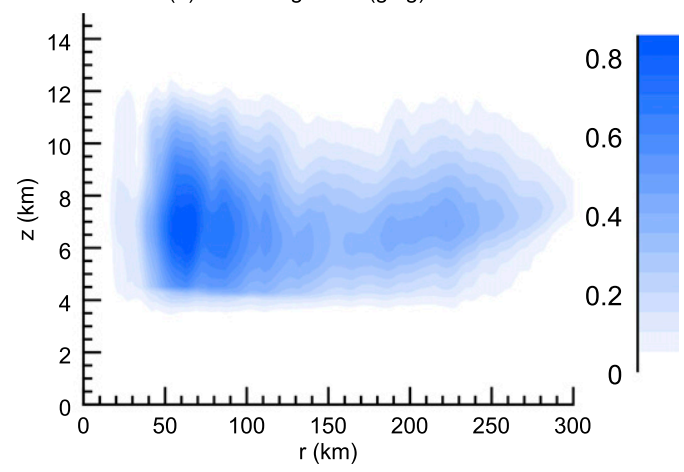

(d) Ice Mixing Ratio $(\mathrm{g} / \mathrm{kg}) \mathrm{r}=3.7$

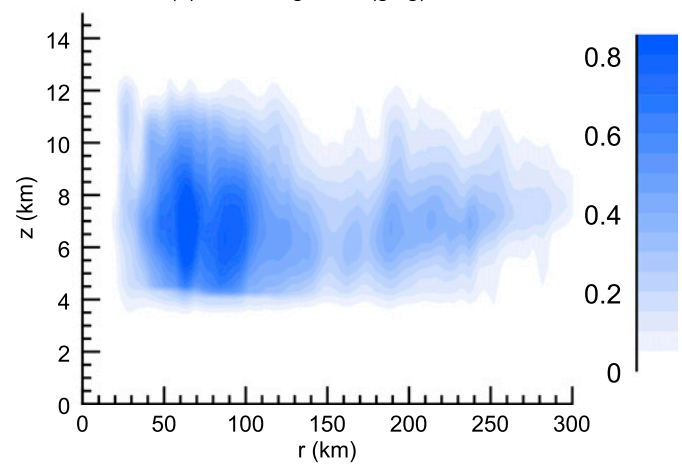

FIG. 1. Azimuthally averaged cross sections of total ice hydrometeor mixing ratio $\left(\mathrm{g} \mathrm{kg}^{-1}\right)$ from the RAD_Medium simulation for (a),(c),(d) all three SST configurations and (b) their mean at a model run time of $36 \mathrm{~h}$.

suppress vertically propagating gravity waves from interacting with the model top, which covers the highest $5 \mathrm{~km}$ of the domain. All nests have two-way feedback enabled and the coarsest grid uses periodic boundary conditions on its zonal and meridional edges. Alternative drag and surface enthalpy coefficient formulations designed for TC applications are employed in all simulations (isftcflx $=1$ ).

To understand when radiation is most important, we run simulations with and without radiation (hereafter "RAD" and "NORAD," respectively) for three different initial vortices. The mathematical formulation for these vortices is given in appendix A. Table 1 provides a summary of these simulations and indicates their initial wind values at the surface and at the height of maximum winds ( $4 \mathrm{~km}$ AGL). The two "Weak" and two "Medium" simulations are run for 5 days, while RAD_Strong is run for 3 days and NORAD_Strong is run for 4 days. These six simulations (hereafter the "core simulations") form the foundation of this paper, but several other simulations are run (discussed in section 3c) that test a supplementary hypothesis that after the vortex core is moistened in a deep layer due to the influence of radiation, radiation becomes less influential in accelerating TCG thereafter.
Unless otherwise specified, all of the following analyses are performed on the 3-km-spaced grid because it spans into the tropical depression's surrounding environment, unlike the $1-\mathrm{km}$ grid, which only covers the

TABLE 2. A list of times it takes (h) for each simulation to reach TCG $\left(12.0 \mathrm{~m} \mathrm{~s}^{-1}\right)$, tropical storm status $\left(17.5 \mathrm{~m} \mathrm{~s}^{-1}\right)$, and hurricane status $\left(33.0 \mathrm{~m} \mathrm{~s}^{-1}\right)$ (TD: tropical depression; TS: tropical storm; $\mathrm{H}$ : hurricane). Wind values are determined as the maximum azimuthally averaged tangential wind about the center point discussed in section $2 \mathrm{~b}$ at the lowest model level (40.6 m AGL). All times are linearly interpolated from 3-h model output spacing and rounded to the nearest hour.

\begin{tabular}{lrcc}
\hline \hline \multicolumn{1}{c}{ Name } & $\begin{array}{c}\text { Genesis } \\
\text { time }\end{array}$ & $\begin{array}{c}\text { TD } \rightarrow \text { TS } \\
\text { time }\end{array}$ & $\begin{array}{c}\text { TS } \rightarrow \text { H } \\
\text { time }\end{array}$ \\
\hline RAD_Weak & 74 & 3 & 19 \\
NORAD_Weak & 120 & - & - \\
NOCRF_Weak & 84 & 6 & 12 \\
RAD_Medium & 41 & 6 & 13 \\
NORAD_Medium & 94 & 4 & 14 \\
RAD_Strong & 32 & 3 & 17 \\
NORAD_Strong & 74 & 4 & 13 \\
RAD_Strong_MOIST & 25 & 5 & 18 \\
NORAD_Strong_MOIST & 30 & 7 & 18 \\
RAD_Strong_MOIST_LL & 48 & 4 & 13 \\
NORAD_Strong_MOIST_LL & 70 & 7 & 11 \\
RAD_Weak_Remove & 78 & 6 & 17 \\
\hline
\end{tabular}


TABLE 3. A list of the time it takes (h) for each simulation to undergo TCG with the different SST configurations discussed in section 2a.

\begin{tabular}{|c|c|c|c|c|}
\hline Simulation name & Constant-SST run & $\operatorname{SST} 1(r=3.7)$ & $\operatorname{SST} 2(r=3.9)$ & Mean simulation \\
\hline RAD_Weak & 70 & 74 & 74 & 74 \\
\hline NORAD_Weak & $>120$ & $>120$ & $>120$ & $>120$ \\
\hline NOCRF_Weak & 88 & 83 & 83 & 84 \\
\hline RAD_Medium & 42 & 41 & 41 & 41 \\
\hline NORAD_Medium & 91 & 94 & 97 & 94 \\
\hline RAD_Strong & 32 & 32 & 32 & 32 \\
\hline NORAD_Strong & 74 & 73 & 73 & 74 \\
\hline RAD_Strong_MOIST & 25 & 25 & 24 & 25 \\
\hline NORAD_Strong_MOIST & 29 & 31 & 31 & 30 \\
\hline RAD_Strong_MOIST_LL & 48 & 49 & 46 & 48 \\
\hline NORAD_Strong_MOIST_LL & 66 & 73 & 77 & 70 \\
\hline RAD_Weak_Remove & 72 & 77 & 82 & 78 \\
\hline
\end{tabular}

core of the vortex. Because of our numerous modifications to an idealized modeling framework, the minimum surface pressure in the domain is initially about $1017 \mathrm{hPa}$. The authors do not expect that the robustness of the following results are impacted by this in any way, despite this value being higher than that of the real atmosphere.

The nature of convection in TCs is in part random and intrinsically unpredictable (e.g., Van Sang et al. 2008), and therefore it is worthwhile to understand how the timing of TCG is impacted by subtle differences in its distribution. To validate that the differences between our simulations are due to changes in radiation and moisture rather than the stochastic distribution of convection, we add modest perturbations to the SST field and perform otherwise identical runs of all the simulations presented herein two times. Running otherwise identical simulations with small SST differences provides insight into how influential and robust the changes in radiation and moisture are as it pertains to the conclusions in this study.

We employ a "chaos sequence" approach to add small (of order $0.1^{\circ} \mathrm{C}$ ) perturbations to the SST field. The value of the perturbation $(x)$ at a given grid cell depends on its value at the previous grid cell according to

$$
x[n+1]=r^{*} x[n]^{*}(1-x[n]),
$$

where $r$ is a constant. The SST is then perturbed according to

$$
\operatorname{SST}[n+1]=28+\left(0.2^{*} x[n+1]\right)-0.1 .
$$

To create two distinct SST fields, we choose $r$ values of 3.7 and 3.9.

Figure 1 shows azimuthally averaged cross sections of total ice hydrometeor mixing ratio from the RAD_Medium simulation at $36-\mathrm{h}$ run time for all three SST configurations
(Figs. 1a,c,d), as well as the mean of all three (Fig. 1b). Although there are subtle differences between all the panels, the mean of the different simulations does a good job capturing the general character of the ice fields across all three SST configurations. The timing of TCG across different SST configurations in all our simulations is given in the next section (Table 3). Hereafter all figures and values presented in this manuscript are produced using the mean of all three simulations performed with different SST values (as depicted in Fig. 1b).

\section{b. Computations}

A relatively simple tracking strategy is adopted for objectively determining a center point for azimuthal

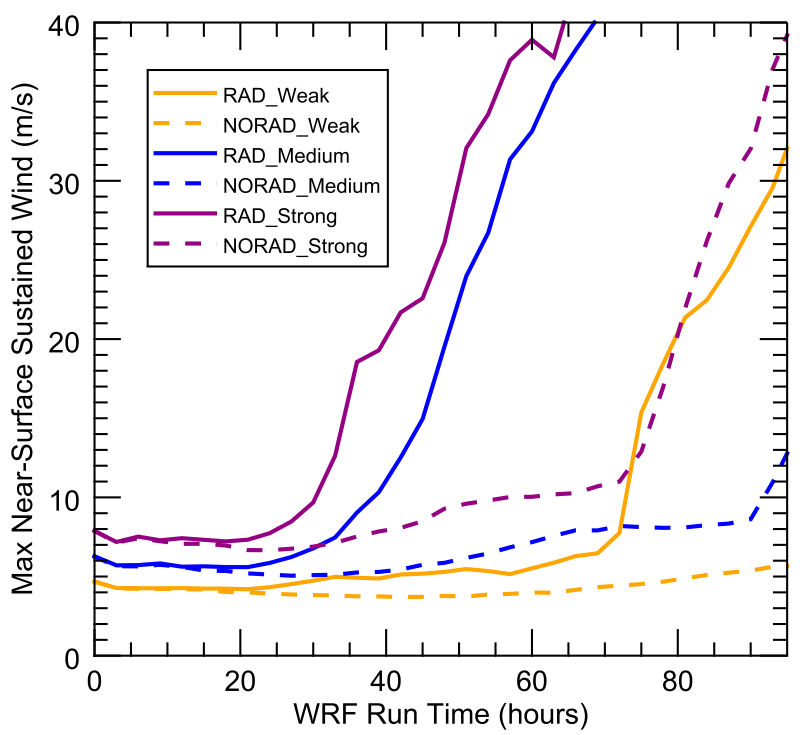

FIG. 2. Time series of the maximum azimuthally averaged tangential wind at the lowest model level (40.6 m AGL) from the six core simulations. 

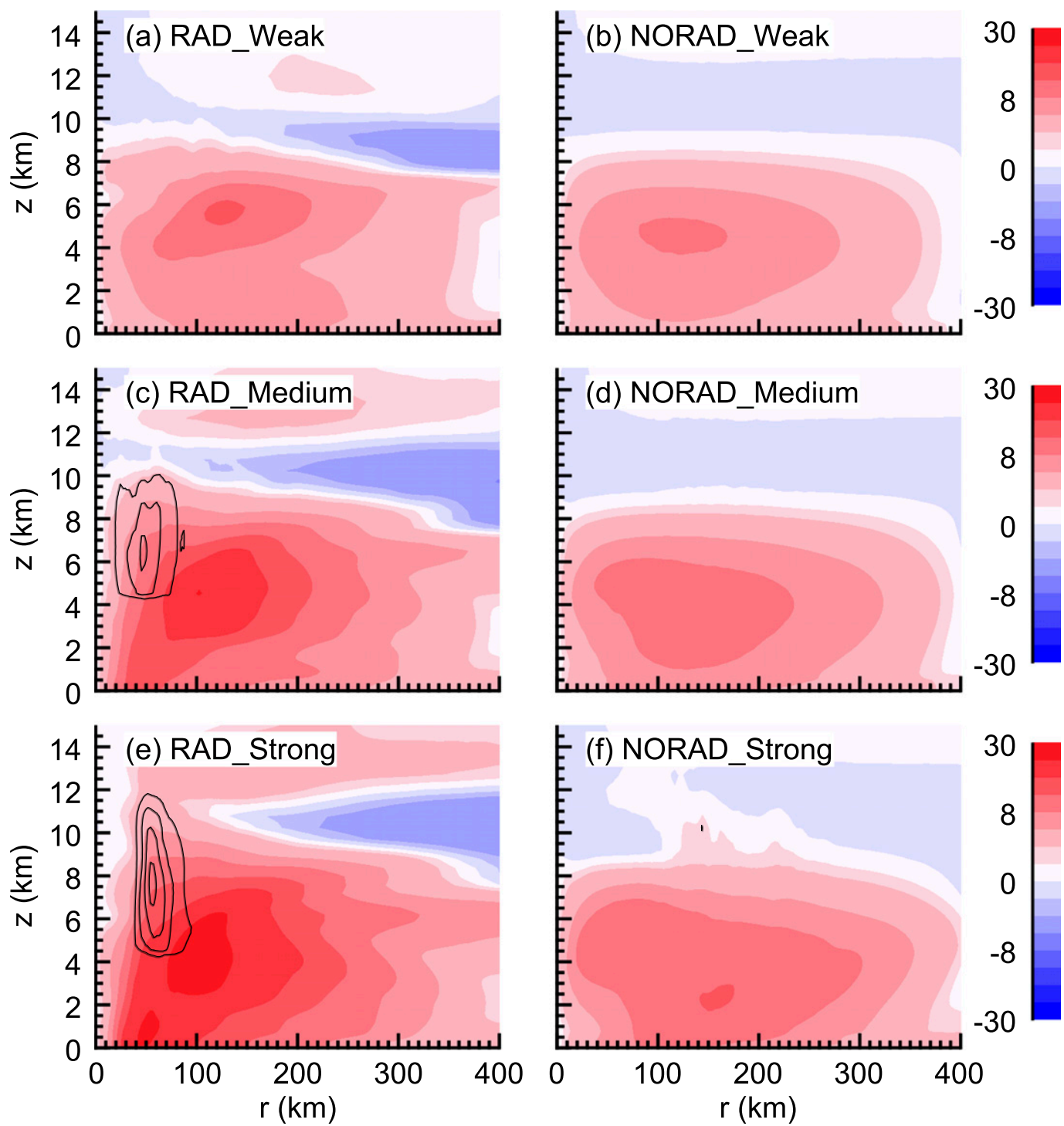

FIG. 3. Azimuthally averaged tangential winds $\left(\mathrm{m} \mathrm{s}^{-1}\right.$; filled contours) and total ice hydrometeor mixing ratio (black lines; increment of $0.25 \mathrm{~g} \mathrm{~kg}^{-1}$ ) from the six core simulations taken at a model run time of $42 \mathrm{~h}$. Simulations are (left) with and (right) without radiation, with (top to bottom) increasing initial vortex strength. Center points for azimuthal averages are determined from the objective methodology given in section $2 \mathrm{~b}$.

average calculations, since a vortex tends to move about in the domain after TCG occurs. First, we smooth the surface pressure field 50 times with a 1-2-1 filter in both the zonal and meridional directions, similar to the approach of Nolan et al. (2009). If the minimum smoothed pressure is below a specified threshold (for which we choose $1013 \mathrm{hPa}$ ), then the location of the minimum is used as the center point. If it is not below this threshold, then the center point is chosen as the location of the maximum initial vertical relative vorticity at the lowest model level (in other words, the original center of the vortex).

There is no widespread quantitative metric for defining if TCG has occurred (e.g., Nolan and McGauley
2012), so this time is determined as the point when the maximum azimuthally averaged tangential wind at the lowest model level (40.6 $\mathrm{m} \mathrm{AGL)} \mathrm{reaches} 12.0 \mathrm{~m} \mathrm{~s}^{-1}$. We note by inspection that once our vortices reach this threshold, the wind (pressure) field is on a rapid rise (decline), supporting our contention that TCG has occurred. A different threshold for TCG could have a modest effect on our results; however, we believe that any threshold we choose will either be somewhat arbitrary or rely on subjectivity, so we have chosen the $12.0 \mathrm{~m} \mathrm{~s}^{-1}$ threshold both to remove human interpretation and to streamline the process of determining TCG across our 36 simulations in this study. We also consider 

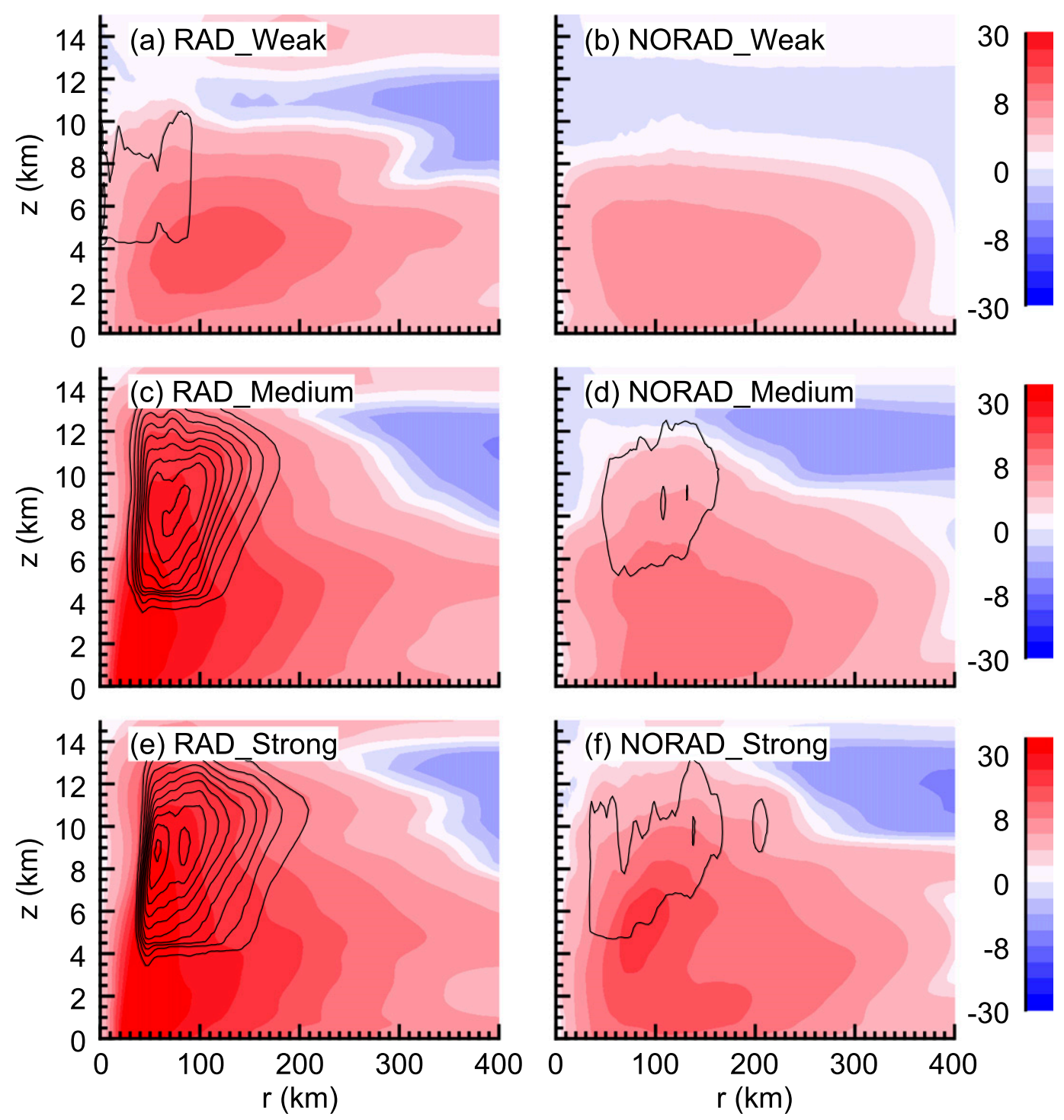

FIG. 4. As in Fig. 3, but at a model run time of $69 \mathrm{~h}$.

the time it takes each vortex to transition from a tropical depression to a tropical storm (upon reaching $17.5 \mathrm{~m} \mathrm{~s}^{-1}$ winds) and from a tropical storm to a hurricane (upon reaching $33.0 \mathrm{~m} \mathrm{~s}^{-1}$ winds). Data are output from WRF at 3-h intervals, so linear interpolation is used to find a more precise value for when each classification is attained, which is then rounded to the nearest hour.

\section{Results}

\section{a. Sensitivity to initial vortex strength}

Table 2 shows the TCG times for all simulations performed in this study. The six core simulations given in Table 1 are listed in the first group, along with a simulation performed using the weak initial vortex that includes radiation but has CRF deactivated (discussed more below). Following those seven simulations are five others that test sensitivity to initial moisture and to shutting off radiation during a run, which are introduced and described in section $3 \mathrm{c}$. Table 3 shows how long it takes each simulation to undergo TCG under the different SST configurations described in section 2 a. It can be seen that, by and large, the simulations presented in this study do not exhibit a strong sensitivity to changes in the location and distribution of convection, thereby suggesting that the experimental design is robust.

Time series of the six core simulations' intensity are shown in Fig. 2 to further highlight their progression. The weakest initial vortex is able to undergo TCG with 

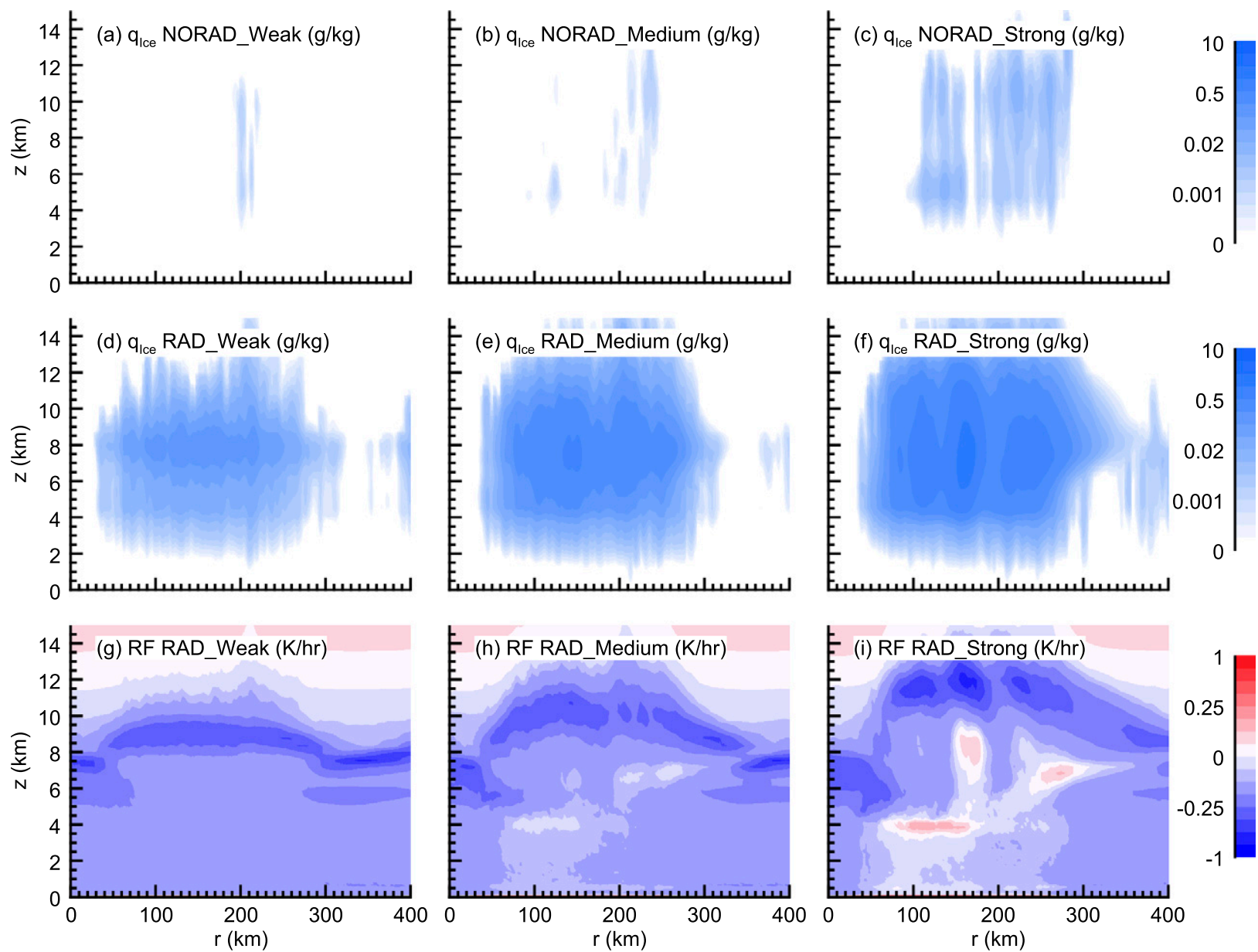

FIG. 5. Azimuthally averaged cross sections of (top),(middle) ice hydrometeor mixing ratio $\left(\mathrm{g} \mathrm{kg}^{-1}\right)$ and (bottom) net radiative forcing $\left(\mathrm{K} \mathrm{h}^{-1}\right)$ from the six core simulations at a model run time of $30 \mathrm{~h}$.

radiation, but fails to do so in the absence of radiation in a 5-day period. The medium-strength and strong initial vortices undergo TCG both with and without radiation within the allotted simulation time, but the absence of radiation delays genesis by about 2 days in both cases. We note, as expected, that strengthening a vortex without modifying radiation allows for TCG to happen faster.

It is interesting to note that the time it takes to go from a tropical depression to a tropical storm and from a tropical storm to a hurricane is not appreciably affected by the presence of radiation. This suggests that the increase in TC intensity is driven by fluxes from the warm ocean below once winds at the surface are sufficiently strong, rather than being driven by any radiative mechanism. Using RAMS, Nicholls (2015) found that radiation did accelerate the transition from a tropical depression to a tropical storm, but this inconsistency might be explained by the different radiation, microphysics, surface flux, and boundary layer parameterizations selected between these two works. More recently, Tang et al. (2019) showed that radiation can appreciably affect the intensification of TCs, but their sensitivity experiments were only performed on solar radiation (daytime and nighttime only) so these studies are not directly comparable in this manner.

Azimuthally averaged tangential wind and ice hydrometeor fields for the six core simulations are shown in Fig. 3 after $42 \mathrm{~h}$ of run time. The RAD_Strong simulation has already undergone TCG and intensified into a tropical storm, and the RAD_Medium simulation is about to do the same. Distinguishable MLVs are present in the RAD_Weak and NORAD_Strong simulations prior to TCG. In addition to observations, MLVs have also been identified in many prior numerical modeling studies (e.g., Reasor et al. 2005; Nolan 2007; Kutty and Gohil 2017). All six core simulations develop a prominent MLV prior to TCG, which may be caused to a large degree by sublimation at the base 


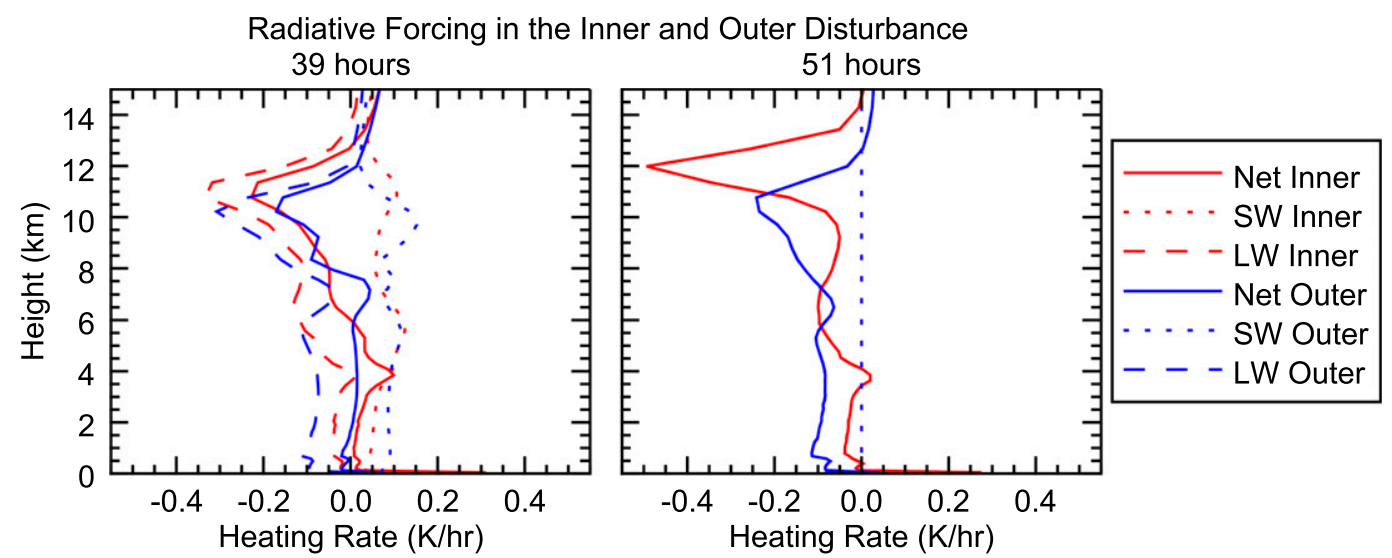

FIG. 6. Vertical profiles of shortwave (dotted), longwave (dashed), and net (solid) radiative forcing in the inner (red) and outer (blue) disturbance from the RAD_Medium simulation at (left) 39-h (daytime) and (right) 51-h (nighttime) model run time. The inner (outer) disturbance is defined as the $0-100-\mathrm{km}(300-400-\mathrm{km})$ radius.

of their stratiform hydrometeor canopies after sufficient convection develops (Nicholls et al. 2018).

Figure 4 shows the same fields as in Fig. 3, but is taken $27 \mathrm{~h}$ later at a model run time of $69 \mathrm{~h}$. By this time hurricanes have formed in the RAD_Strong and RAD_Medium simulations, and TCG is imminent in the RAD_Weak and NORAD_Strong simulations evidenced by strong winds and pronounced MLVs. Although the NORAD_Medium simulation has made some marginal progress, the NORAD_Weak simulation shows virtually no sign of development. Simulations with radiation develop ice canopies much faster, indicating that convective activity is favored when radiation is included. These results suggest that radiation is very influential at the very early stages of TCG, but as a vortex gets stronger radiation is decreasingly important. In the next subsection we examine more specific details about how radiation influences these developing vortices.

\section{b. Sensitivity to radiation}

In the previous subsection we show that a vortex is able to undergo TCG without the influence of radiation for a sufficiently strong initial vortex, but in all simulations TCG is delayed significantly compared to simulations with radiation included. In this subsection we explore the impact that radiation has on accelerating TCG, in particular its influence on convective activity. Azimuthally averaged cross sections of total ice hydrometeors and net radiative forcing from the six core simulations at a model run time of $30 \mathrm{~h}$ are shown in Fig. 5, as the first full night is ending in the simulation. As expected, a stronger initial vortex produces larger mixing ratios aloft from increased surface fluxes (cf. Figs. 5a-c and Figs. 5d-f). However, even for the strongest initial vortex, surface fluxes alone are not sufficient to rapidly produce an ice canopy without radiation included (cf. Fig. 5c and Fig. 5f).

Once a stratiform ice canopy develops, it is hypothesized that a weak transverse circulation forms that is driven by the radial gradient of nighttime longwave cooling. This circulation is marked by upward motion in the core and subsidence in the surroundings, which slowly moistens the core and favors convection (Nicholls 2015). This radial gradient of cooling is visible in Figs. $5 \mathrm{~g}-\mathrm{i}$, with the core experiencing less cooling than the surrounding environment beneath a height of $8 \mathrm{~km}$ AGL because the hydrometeor canopies have a higher emissivity than clear sky. As expected, this mechanism is stronger with a more developed hydrometeor canopy (cf. Figs. 5e,f, and Figs. 5h,i). The expected general structure of tropical radiative forcing (strong nocturnal infrared cooling at the cloud top and warming at the cloud base) is seen in these simulations (Webster and Stephens 1980).

Vertical profiles of shortwave, longwave and net radiative forcing in the inner and outer disturbance from the RAD_Medium simulation are shown in Fig. 6 in order to explore the difference between nighttime and daytime contributions of the differential radiative forcing mechanism. At night (right panel), there is significantly more radiative cooling in the environment than in the core beneath a height of $6 \mathrm{~km}$, as shown before in Fig. 5. The daytime (left) panel shows similar contribution from the longwave as the nighttime panel, and that there is more shortwave heating in the environment than the core. Increased shortwave heating in the environment subdues and counteracts the differential longwave mechanism during the daytime. However, the daytime net forcing field still shows that the environment has a 
greater cooling tendency than the core. This suggests that the beneficial effects of longwave radiation overwhelm the documented detrimental effects of shortwave radiation on TCG (e.g., Tang and Zhang 2016). We can also note from Fig. 6 that the low- to midlevel nocturnal cooling tendency in WRF $\left(0.1 \mathrm{~K} \mathrm{~h}^{-1}\right)$ is of similar magnitude to that observed in the tropics $\left(0.06-0.08 \mathrm{~K} \mathrm{~h}^{-1}\right.$; from Fig. 13 of Gray and Jacobson 1977), suggesting that this process is being represented realistically in the model. This analysis indicates that the longwave differential forcing mechanism is important in promoting inner-core moisture formation in a developing tropical depression.

We perform a simulation with the weak initial vortex and radiation activated but CRF disabled (NOCRF_Weak) to further support the hypothesis that radiative heating by hydrometeors is influential in TCG. In other words, longwave and shortwave radiation do not interact with hydrometeors in this simulation. As given in Table 2, this simulation takes $84 \mathrm{~h}$ to undergo genesis, which is considerably different than the $74 \mathrm{~h}$ it takes with CRF activated. This suggests that radiation's interaction with hydrometeors is important in TCG. It is worth clarifying that longwave radiation in the simulation without CRF still responds to the enhanced vapor mixing ratio in the core, which may still lead to a subdued version of the transverse circulation mechanism. It stands to reason that without the influence of enhanced RH, the difference in genesis time between the RAD_Weak and NOCRF_Weak simulations would be even greater than observed herein.

The diurnal cycle of radiation has a significant impact on tropical convection, with activity suppressed during daylight hours and low-level moistening occurring overnight (e.g., Jacobson and Gray 1976). The latter mechanism is hypothesized to be responsible for an early morning maximum in convective activity (Gray and Jacobson 1977). Figure 7 shows time series of ice mass and outgoing longwave radiation from the disturbance core and surrounding environment in the RAD_Medium simulation. A clear diurnal cycle of ice mass is present with an early morning maximum (Fig. 7a), as evidenced by the peaks of the time series occurring at approximately 0600 local time as the sun is rising in the domain (dashed vertical lines). This indicates that our study is consistent with the observed tropical diurnal cycle mechanism. Figure $7 \mathrm{~b}$ shows the radial gradient of nighttime longwave cooling, indicating that the cloudy core of the disturbance (less than $300 \mathrm{~km}$ from the center) prevents more longwave radiation from reaching the model top than the surrounding environment does, which supports the nocturnal transverse circulation hypothesis (Nicholls 2015). (a) Total Ice Mass

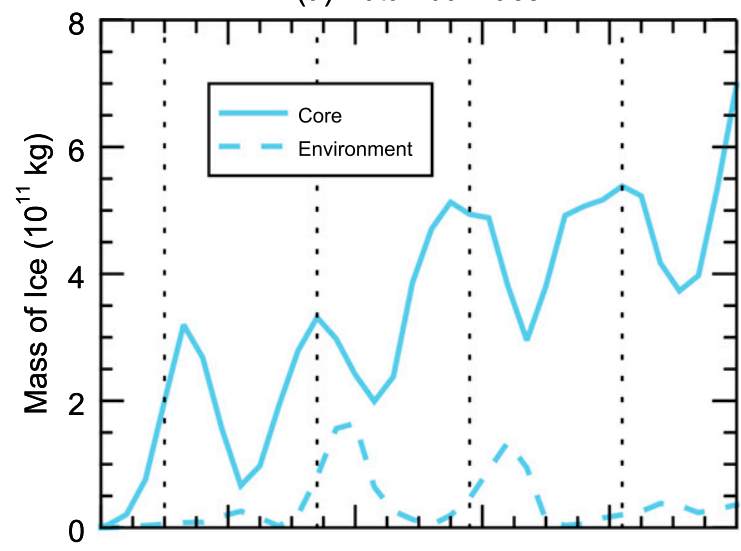

(b) Outgoing Longwave Radiation

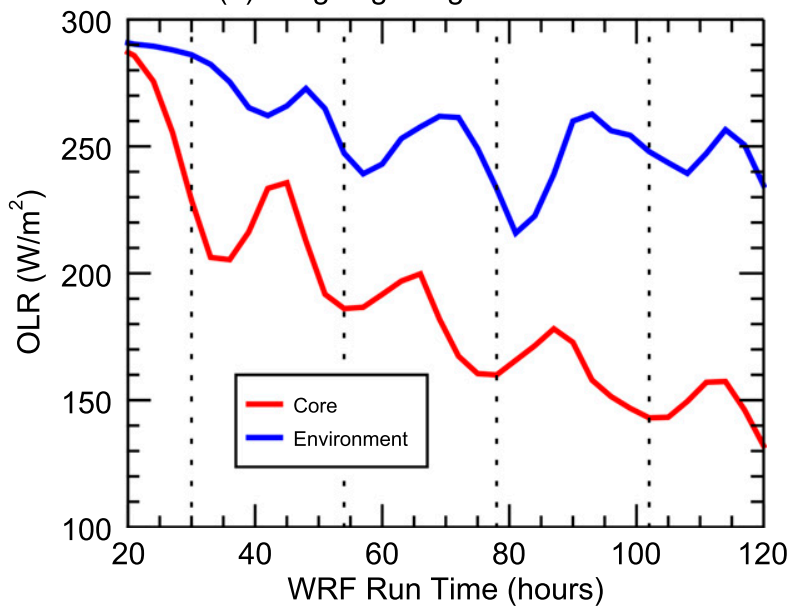

FIG. 7. (a) Time series of total ice mass calculated within concentric boxes of $600 \mathrm{~km} \times 600 \mathrm{~km}$ (solid line) and $900 \mathrm{~km} \times$ $900 \mathrm{~km}$ (dashed line). The latter box does not include ice mass from within the former box in order to separate between core and environment contributions. (b) Time series of outgoing longwave radiation at the model top averaged inside (red) and outside (blue) of a $300-\mathrm{km}$ radius. Both panels are taken from the RAD_Medium simulation. Vertical dashed lines indicate 0600 local time for reference. This figure is produced using data from the $15-\mathrm{km}$-spaced grid.

The change in $\mathrm{RH}$ in the RAD_Medium and NORAD_Medium simulations from 0 - to 36 -h run time is shown in Fig. 8. Both simulations have undergone low-level moistening, but there is a very large difference between the two simulations above $6 \mathrm{~km}$ AGL: the simulation with radiation has undergone a significant moistening at upper levels. The RAD_Medium vortex is primed for TCG, which happens just $5 \mathrm{~h}$ later, while the simulation without radiation takes more than 2 more days to follow suit. This result is consistent with Rappin et al. (2010), who noted that TCG occurs when the storm's core becomes nearly saturated. We hypothesize that the presence of 

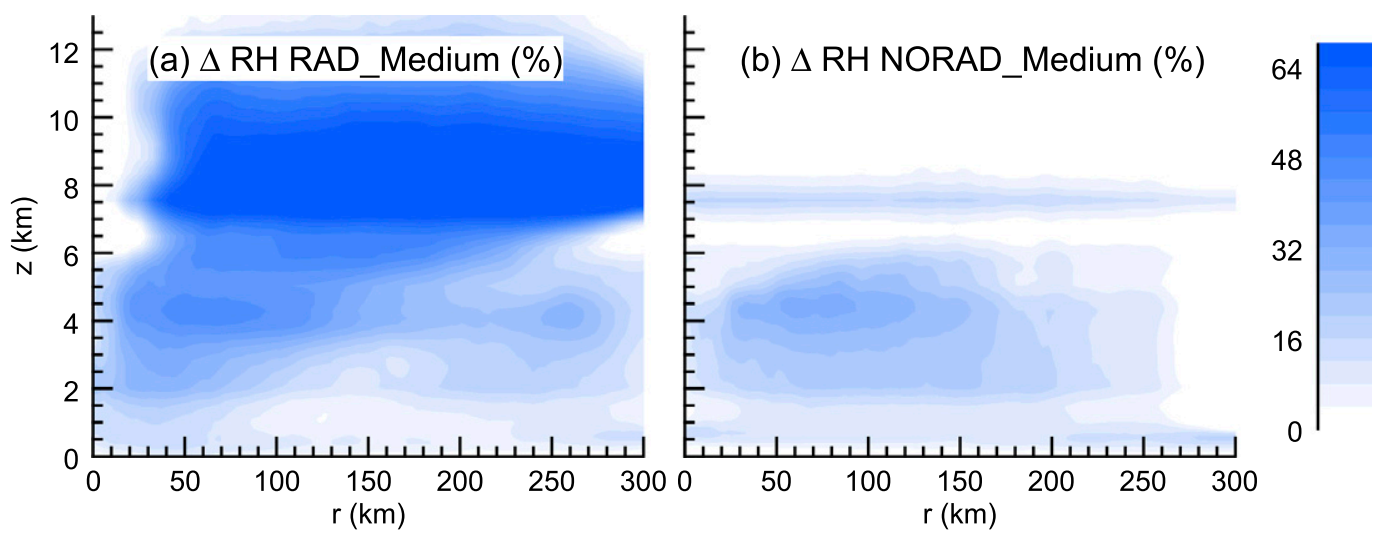

FIG. 8. Azimuthally averaged cross sections of the change in $\mathrm{RH}$ from 0 - to 36 -h run time in the (a) RAD_Medium and (b) NORAD_Medium simulations.

radiation enhances convection that leads to rapid deep moistening in a simulation, which is then favorable for TCG regardless of the continued influence of radiation. The next subsection introduces several supplementary simulations that support this claim.

\section{c. Sensitivity to moisture}

We show in the previous two subsections that all else equal, radiation has less influence on the timing of TCG for a stronger initial vortex, but as seen in Fig. 2 and Table 2 there is still a large disparity between runs with and without radiation. Figure 8 highlights a key difference between simulations with and without radiation: deep moistening of the vortex core occurs more readily with radiation included, which we hypothesize allows a vortex to undergo TCG even without the presence of radiation thereafter. Here we undertake five additional simulations that validate this claim.

Four additional simulations, which we name RAD_Strong_MOIST, NORAD_Strong_MOIST, RAD_Strong_MOIST_LL, and NORAD_Strong_MOIST_LL (where "LL" signifies "low level"), are simulated that have identical initial vortices and physics parameterizations to the RAD_Strong and NORAD_Strong simulations except that the initial sounding from Jordan (1958) is moistened. In the "MOIST" ("MOIST_LL") runs, the sounding is moistened in a deep (shallow) layer. The exact modifications to the sounding are given in appendix B. The "MOIST" simulations mimic the core moistening that occurs faster in simulations with radiation due to enhanced convective activity to verify that radiation still accelerates development once a vortex reaches that point. The "MOIST_LL" simulations are run to emphasize that moistening must be in a deep layer before radiation becomes less important in TCG.
Figure 9 shows the same time series as Fig. 2, but for only the "Strong" initial vortices with and without the deep-moisture anomaly. The purple curves are identical to those in Fig. 2. For the deep-moistened initial sounding (green curves), the presence of radiation only makes a small difference in the progression of these simulations. Table 2 also confirms that TCG occurs at nearly the same time with and without radiation, compared to a 42-h difference for the default sounding. The similarity between the deep-moistened simulations suggests that once a vortex is sufficiently strong and moist, radiation does not play a significant role in its development or early intensification. It is worth noting that regardless of the initial moisture field,

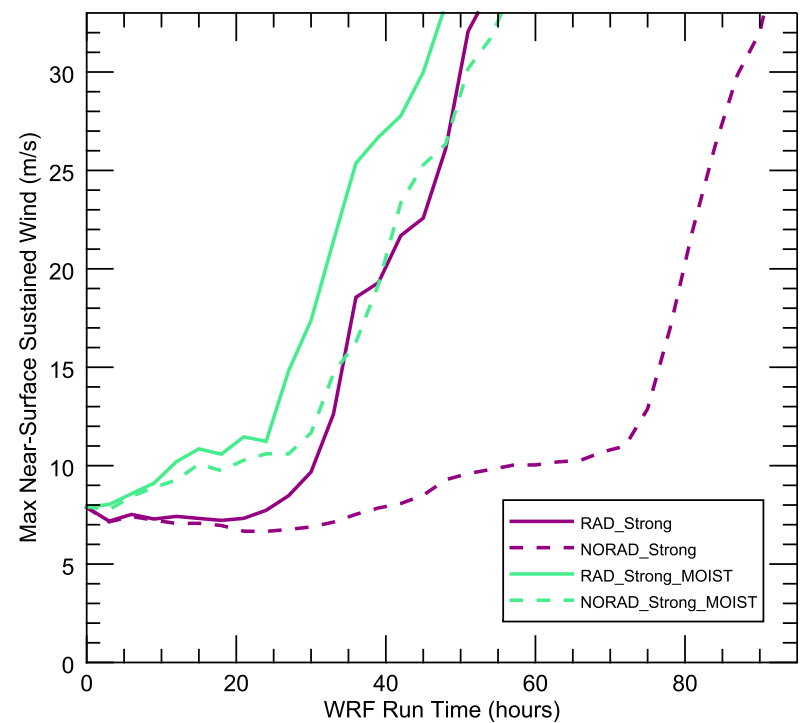

FIG. 9. As in Fig. 2, but for the four "Strong" initial vortex simulations. Time series in purple (green) show simulations with the default (deep-moistened) initial sounding described in appendix B. The purple curves are exactly the same as those pictured in Fig. 2. 

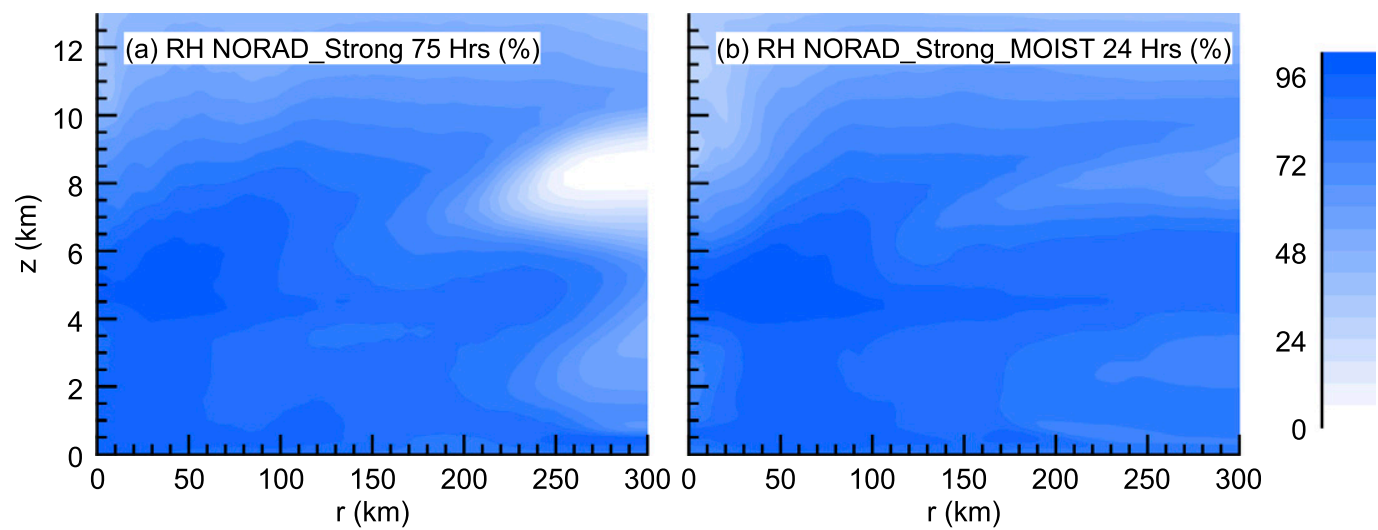

FIG. 10. Azimuthally averaged cross sections of RH from the (a) NORAD_Strong simulation at $75 \mathrm{~h}$ and (b) NORAD_Strong_MOIST simulation at $24 \mathrm{~h}$.

TCG occurs once the core moisture reaches a certain threshold. This is illustrated in Fig. 10, where fields of $\mathrm{RH}$ are qualitatively similar at the respective genesis times in two simulations. This supports the claim that the moisture increase in these simulations is in line with that of the six core simulations when they reach TCG.

To emphasize that moisture must be enhanced in a deep layer before TCG ceases to depend on radiation, we run two simulations with extra moisture applied to the initial sounding only in the lowest $2 \mathrm{~km}$ AGL (denoted by "MOIST_LL"). Table 2 shows that TCG is delayed by $22 \mathrm{~h}$ in these simulations without the presence of radiation. It therefore appears that a vortex must have a deep layer of moisture before radiation becomes less important in its development. It is worth noting that RAD_Strong_MOIST_LL simulation takes longer to undergo TCG than the RAD_Strong simulation, which has no low-level moisture anomaly. This is likely due to some combination of a subdued latent heat flux from the sea surface and weaker nocturnal radiative cooling in the disturbance's surrounding environment (not shown). Although the enhanced low-level moisture promotes strong convection at first, it is likely that these processes delay the formation of upper-level moisture and thus TCG.

To further validate the conclusion that radiation makes less of a difference once the core of a vortex is sufficiently moist, we rerun the RAD_Weak simulation but shut off radiation permanently after $66 \mathrm{~h}$ of model integration. This simulation is named RAD_Weak_Remove because radiation is removed during its evolution. The objective of this is to see if $66 \mathrm{~h}$ of radiative forcing in this framework provides sufficient deep moistening to allow for TCG to occur. With radiation left on (as in RAD_Weak), TCG happens just hours after this point, and without radiation from the beginning (NORAD_Weak) at least another $54 \mathrm{~h}$ passes without TCG occurring.

Figure 11 provides the same time series as Fig. 2, but for all three "Weak" vortex cases, including the run described above where radiation is switched off (RAD_Weak_Remove). TCG occurs just $12 \mathrm{~h}$ after radiation is disabled in RAD_Weak_Remove (see Table 2) compared to $8 \mathrm{~h}$ later in RAD_Weak, lending support to the conclusion that the influence of radiation for the first $66 \mathrm{~h}$ "primes" the vortex for TCG. This must be true because the simulation that began without radiation (NORAD_Weak) is unable to undergo TCG within 5 days. To indicate the

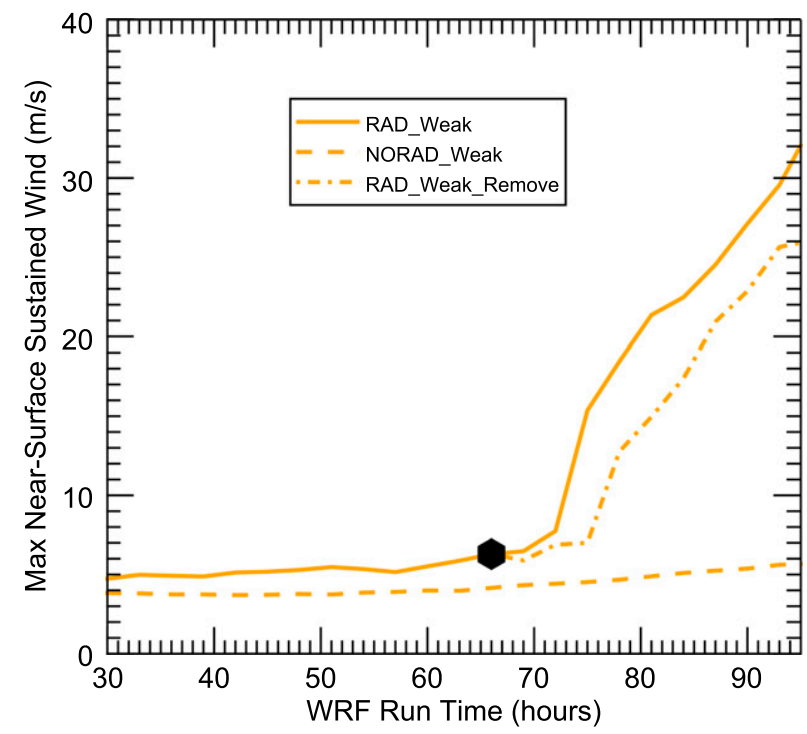

FIG. 11. As in Fig. 2, but for the three "Weak" simulations. The solid and dashed curves are exactly the same as those pictured in Fig. 2. The dash-dotted curve shows a simulation that ran with radiation for the first $66 \mathrm{~h}$, at which point radiation is turned off. This point is marked with the black hexagon. 

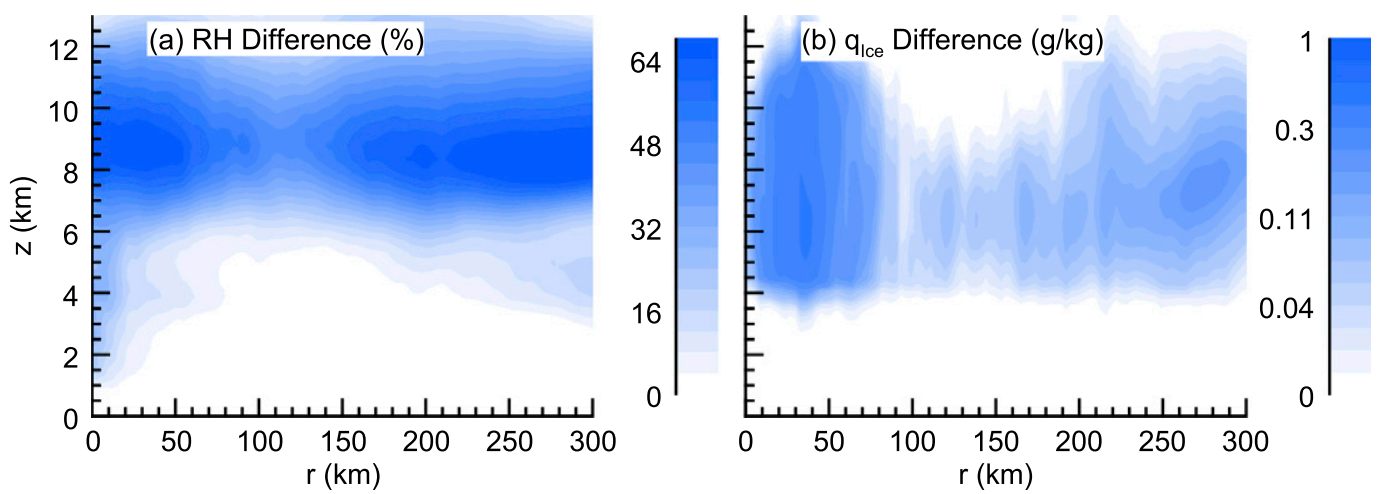

FIG. 12. Azimuthally averaged cross sections of the difference in (a) RH and (b) ice mixing ratios between the RAD_Weak and NORAD_Weak simulations at 66-h run time. It is after this time that radiation is turned off in the RAD_Weak_Remove simulation.

role that radiation plays for the first $66 \mathrm{~h}$ in this framework, Fig. 12 shows difference fields of RH and ice mixing ratio between RAD_Weak and NORAD_Weak at the point where radiation is turned off in RAD_Weak_Remove. This suggests that the presence of radiation accelerates deep moistening in the core of the vortex, and a robust canopy of ice is a noticeable by-product of this. The five supplementary simulations introduced in this subsection provide support that, in our modeling framework, radiation primarily serves to enhance convection thereby accelerating moistening in the core over a deep layer in preparation for TCG and is much less important thereafter.

\section{Conclusions}

A numerical modeling investigation of the influence of longwave and shortwave radiation on tropical cyclogenesis (TCG) is undertaken for varying strengths of initial vortices, with the aim at understanding when radiation is most important in promoting TCG. This is done by running simulations with and without radiation for three different initial vortices. We find that for a weak vortex, TCG occurs in about 3 days with radiation but is inhibited for more than 5 days without radiation. For the two stronger initial vortices, TCG is able to occur with and without radiation within 4 days, but experiences a delay of about 2 days without radiation included, thus suggesting that a strong vortex still requires the influence of radiation to undergo TCG readily. A strong diurnal cycle of convective activity is evident in our simulations, consistent with previous observational and modeling studies (e.g., Gray and Jacobson 1977; Davis and Ahijevych 2012; Dunion et al. 2019). We also find that radiation does not have an appreciable effect on the timing of early intensification (reaching tropical storm and hurricane status) in our modeling framework.
Although other recent modeling studies have found that early intensification may be impacted by radiation (e.g., Melhauser and Zhang 2014; Nicholls 2015; Tang et al. 2019), the experimental designs in these studies cannot be directly compared to the one presented herein, so we are not in direct contradiction with these prior works. However, this result motivates the need for additional studies to investigate the role of radiation on early intensification of TCs. We also note that our simulations are not initialized with any ambient vertical wind shear or mean flow, which could be important when considering radiation's impact on TCG and should be a topic of future work.

For an identical initial vortex, simulations with radiation develop deep-moisture anomalies (extending into the middle troposphere) and hydrometeor canopies faster compared to their counterparts without radiation. This finding is largely consistent with the results of Nicholls (2015), who found that simulations with radiation tend to have increased $\mathrm{RH}$ and increased low-level cyclonic circulation. A differential radiative forcing between the cloudy disturbance core and its clear-sky surroundings appears to be important in providing enhanced moisture for the disturbance and destabilizing the core, similar to the mechanism described by Gray and Jacobson (1977). Convergence of low-level moisture provides an avenue for deep moistening of a tropical disturbance. Once the core is sufficiently moistened in a deep layer, the impact of radiation recedes, shown through additional simulations that are premoistened as well as a simulation where radiation is turned off just prior to TCG occurring.

It stands to reason from the arguments presented herein that radiation has the largest influence on TCG at very early stages of a disturbance's development. It also emerges that its primary influence is to provide a catalyst 
for deep moistening in the core, since radiation does not play a significant role once the core is moistened in a deep layer. This work shows the importance of accurately simulating radiation and moisture, and provides insight into how much care should be taken to consider radiative processes at different stages of a TC's development during operational forecasting. Based on our results, we conclude that radiation's influence is strongest for disturbances that have broad clear-sky regions surrounding them and fairly axisymmetric cloud canopies. These favor a strong differential radiative forcing and thus a heightened low-level moisture convergence from the surroundings. Additional work is required to validate these conclusions in other modeling frameworks and with different choices of physics schemes. A forthcoming publication will examine the relevance of these findings on a numerical modeling case study of the formation of a real hurricane.

Acknowledgments. This work was supported by the National Science Foundation under Grant NSF AGS 1445875. We acknowledge high-performance computing support from Cheyenne (https://doi.org/10.5065/ D6RX99HX) provided by NCAR's Computational and Information Systems Laboratory, sponsored by the National Science Foundation. We thank Drs. Katja Friedrich, Gregory Thompson, and John Cassano for their helpful discussions, and Robinson Wallace for his help with developing the visualization code, which was modified from code originally developed by Professor Mike Montgomery and his research group at Colorado State University.

\section{APPENDIX A}

\section{The Initial Vortex}

The default vortex in the tropical cyclone "test" case in WRF is based on that used in Rotunno and Emanuel (1987) and has maximum horizontal winds at the surface. These surface winds are linearly interpolated to reach zero at a height specified by the user. We modify this vertical interpolation to be similar to the method in Montgomery et al. (2006) so that our vortex more closely matches the initial RAMS vortex employed by other recent idealized modeling studies of TCG (Nicholls and Montgomery 2013; Nicholls 2015; Nicholls et al. 2018). Now, the vortex is defined by

$$
\begin{aligned}
v(r, z)= & v_{\text {sfc }}(r)\left\{A\left[\cos \left(\frac{\pi z}{H}\right)+1\right]\right. \\
& \left.-B\left[\cos \left(\frac{2 \pi z}{H}\right)-1\right]\right\},
\end{aligned}
$$

where

$$
v_{\mathrm{scc}}(r)=\sqrt{\left(\frac{v_{\max } r}{r_{\max }}\right)^{2}\left[\left(\frac{2 r_{\max }}{r+r_{\max }}\right)^{3}-\left(\frac{2 r_{\max }}{r_{0}+r_{\max }}\right)^{3}\right]+\frac{1}{4} f^{2} r^{2}}-\frac{1}{2} f r .
$$

In Eqs. (A1) and (A2), $A$ and $B$ are scalars, $H$ is the height of the vortex (above which the wind speeds are zero), $v_{\max }$ is the maximum value of the vortex winds, $r_{\text {max }}$ is the radius of maximum winds, $r_{0}$ is the maximum radius occupied by the vortex (outside which the wind speeds are zero), and $f$ is the Coriolis parameter, all of which are specified by the user. For our simulations, we choose the following values: $A=0.5, B=0.7, H=$ $9.5 \mathrm{~km}, r_{\max }=125 \mathrm{~km}, r_{0}=400 \mathrm{~km}$, and $f=3.8 \times$ $10^{-5} \mathrm{~s}^{-1}$ (corresponding to $15^{\circ} \mathrm{N}$ latitude). To produce three different initial vortex strengths, we chose values for $v_{\max }=7.0,8.8$, and $10.6 \mathrm{~m} \mathrm{~s}^{-1}$ (corresponding to the "Weak," "Medium," and "Strong" initial vortices, respectively). Because of the new vertical interpolation method we employ [Eq. (A1)], these values chosen for $v_{\text {max }}$ do not match the actual maximum winds found in the domain initially; the values that do result are those listed in Table 1. Because this vortex formulation is designed to exist in azimuthal $(r, z)$ space, WRF-ARW "unravels" this vortex into three-dimensional space so that a simulation may be run.

\section{APPENDIX B}

\section{Modification to the Jordan Sounding for "MOIST" Runs}

To validate the hypothesis that a sufficiently strong initial vortex with a deep-moisture anomaly would develop in about the same time regardless of the influence of radiation, we modify the horizontally homogeneous initial sounding used in the model for four model runs ("RAD_Strong_MOIST," "NORAD_Strong_MOIST," "RAD_Strong_MOIST_LL," and "NORAD_Strong_LLMOIST"; see Table 2 and section $3 \mathrm{c}$ ). Table B1 shows the vapor mixing ratios from 
TABLE B1. Water vapor mixing ratios from the default sounding used in the idealized tropical cyclone "test" case in WRF (Jordan 1958; column 2) and from the new soundings used for the deep-moistened ("MOIST"; column 3) and low-levelmoistened ("MOIST_LL"; column 4) simulations in this work. The difference between the modified/moistened sounding and the default value is given in parentheses.

\begin{tabular}{|c|c|c|c|}
\hline $\begin{array}{l}\text { Height } \\
\text { (m) }\end{array}$ & $\begin{array}{c}\text { Jordan (1958) } \\
\text { default } \\
\text { sounding }\left(\mathrm{g} \mathrm{kg}^{-1}\right)\end{array}$ & $\begin{array}{c}\text { Deep- } \\
\text { moistened } \\
\text { sounding }\left(\mathrm{g} \mathrm{kg}^{-1}\right)\end{array}$ & $\begin{array}{c}\text { Low-level- } \\
\text { moistened } \\
\text { sounding }\left(\mathrm{g} \mathrm{kg}^{-1}\right)\end{array}$ \\
\hline 0 & 18.2 & $20.2(2.0)$ & $20.2(2.0)$ \\
\hline 583 & 15.3 & $17.3(2.0)$ & $17.3(2.0)$ \\
\hline 1547 & 11.0 & $13.0(2.0)$ & $12.0(1.0)$ \\
\hline 2609 & 7.1 & $9.1(2.0)$ & $7.1(0.0)$ \\
\hline 3792 & 4.6 & $6.6(2.0)$ & $4.6(0.0)$ \\
\hline 5138 & 3.2 & $5.2(2.0)$ & $3.2(0.0)$ \\
\hline 6703 & 1.4 & $3.0(1.6)$ & $1.4(0.0)$ \\
\hline 8581 & 0.0 & $0.6(0.6)$ & $0.0(0.0)$ \\
\hline 10935 & 0.0 & $0.0(0.0)$ & $0.0(0.0)$ \\
\hline
\end{tabular}

the moistened soundings next to those of the default Jordan (1958) sounding used in all other simulations, with difference values provided in parentheses.

\section{REFERENCES}

Bister, M., and K. A. Emanuel, 1997: The genesis of Hurricane Guillermo: TEXMEX analyses and a modeling study. Mon. Wea. Rev., 125, 2662-2682, https://doi.org/10.1175/1520-0493(1997) $125<2662$ :TGOHGT $>2.0$. CO 2 .

Bu, Y. P., R. G. Fovell, and K. L. Corbosiero, 2014: Influence of cloud-radiative forcing on tropical cyclone structure. J. Atmos. Sci., 71, 1644-1662, https://doi.org/10.1175/JASD-13-0265.1.

Craig, G. C., 1996: Numerical experiments on radiation and tropical cyclones. Quart. J. Roy. Meteor. Soc., 122, 415-422, https:// doi.org/10.1002/qj.49712253006.

Davis, C. A., 2015: The formation of moist vortices and tropical cyclones in idealized simulations. J. Atmos. Sci., 72, 34993516, https://doi.org/10.1175/JAS-D-15-0027.1.

— , and D. A. Ahijevych, 2012: Mesoscale structural evolution of three tropical weather systems observed during PREDICT. J. Atmos. Sci., 69, 1284-1305, https://doi.org/10.1175/JAS-D11-0225.1.

Dudhia, J., 1989: Numerical study of convection observed during the Winter Monsoon Experiment using a mesoscale two-dimensional model. J. Atmos. Sci., 46, 3077-3107, https://doi.org/10.1175/15200469(1989)046<3077:NSOCOD>2.0.CO;2.

Dunion, J. P., C. D. Thorncroft, and C. S. Velden, 2014: The tropical cyclone diurnal cycle of mature hurricanes. Mon. Wea. Rev., 142, 3900-3919, https://doi.org/10.1175/MWR-D-13-00191.1.

- — - and D. S. Nolan, 2019: Tropical cyclone diurnal cycle signals in a hurricane nature run. Mon. Wea. Rev., 147, 363388, https://doi.org/10.1175/MWR-D-18-0130.1.

Duran, P., and J. Molinari, 2019: Tropopause evolution in a rapidly intensifying tropical cyclone: A static stability budget analysis in an idealized axisymmetric framework. J. Atmos. Sci., 76, 209-229, https://doi.org/10.1175/JAS-D-18-0097.1.
Fingerhut, W. A., 1978: A numerical model of a diurnally varying tropical cloud cluster disturbance. Mon. Wea. Rev., 106, 255-264, https://doi.org/10.1175/1520-0493(1978)106<0255: ANMOAD $>2.0 . \mathrm{CO} ; 2$.

Fovell, R. G., Y. P. Bu, K. L. Corbosiero, W. Tung, Y. Cao, H.-C. Kuo, L. Hsu, and H. Su, 2016: Influence of cloud microphysics and radiation on tropical cyclone structure and motion. Multiscale Convection-Coupled Systems in the Tropics: A Tribute to Dr. Michio Yanai, Meteor. Monogr., No. 56, Amer. Meteor. Soc., https://doi.org/10.1175/AMSMONOGRAPHSD-15-0006.1.

Godbole, R. V., 1973: On destabilization of clouds by radiative cooling. Mon. Wea. Rev., 101, 496-500, https://doi.org/10.1175/ 1520-0493(1973)101<0496:ODOCBR > 2.3.CO;2.

Gray, W. M., 1968: Global view of the origin of tropical disturbances and storms. Mon. Wea. Rev., 96, 669-700, https://doi.org/10.1175/ 1520-0493(1968)096<0669:GVOTOO > 2.0.CO;2.

— , and R. W. Jacobson Jr., 1977: Diurnal variation of deep cumulus convection. Mon. Wea. Rev., 105, 1171-1188, https://doi.org/ 10.1175/1520-0493(1977)105<1171:DVODCC >2.0.CO;2.

Harr, P. A., and R. L. Elsberry, 1996: Structure of a mesoscale convective system embedded in Typhoon Robyn during TCM-93. Mon. Wea. Rev., 124, 634-652, https://doi.org/ 10.1175/1520-0493(1996)124<0634:SOAMCS > 2.0.CO;2.

Hendricks, E. A., M. T. Montgomery, and C. A. Davis, 2004: The role of "vortical" hot towers in the formation of Tropical Cyclone Diana (1984). J. Atmos. Sci., 61, 1209-1232, https://doi.org/ 10.1175/1520-0469(2004)061<1209:TROVHT>2.0.CO;2.

Hong, S.-Y., Y. Noh, and J. Dudhia, 2006: A new vertical diffusion package with an explicit treatment of entrainment processes. Mon. Wea. Rev., 134, 2318-2341, https://doi.org/ 10.1175/MWR3199.1.

Iacono, M. J., J. S. Delamere, E. J. Mlawer, M. W. Shephard, S. A. Clough, and W. D. Collins, 2008: Radiative forcing by longlived greenhouse gases: Calculations with the AER radiative transfer models. J. Geophys. Res., 113, D13103, https://doi.org/ 10.1029/2008JD009944.

Jacobson, R. W., and W. M. Gray, 1976: Diurnal variation of oceanic deep cumulus convection. Colorado State University Atmospheric Science Paper 243, 110 pp.

Jordan, C. L., 1958: Mean soundings for the West Indies area. J. Meteor., 15, 91-97, https://doi.org/10.1175/1520-0469(1958) 015<0091:MSFTWI >2.0.CO;2.

Kilroy, G., R. K. Smith, and M. T. Montgomery, 2017: A unified view of tropical cyclogenesis and intensification. Quart. J. Roy. Meteor. Soc., 143, 450-462, https://doi.org/10.1002/QJ.2934.

,-- , and,- 2018 : The role of heating and cooling associated with ice processes on tropical cyclogenesis and intensification. Quart. J. Roy. Meteor. Soc., 144, 99-114, https:// doi.org/10.1002/qj.3187.

Knaff, J. A., C. J. Slocum, and K. D. Musgrave, 2019: Quantification and exploration of diurnal oscillations in tropical cyclones. Mon. Wea. Rev., 147, 2105-2121, https://doi.org/10.1175/MWR-D-180379.1.

Kraus, E. B., 1963: The diurnal precipitation change over the sea. J. Atmos. Sci., 20, 551-556, https://doi.org/10.1175/1520-0469(1963) $020<0551$ :TDPCOT $>2.0 . \mathrm{CO} ; 2$

Kutty, G., and K. Gohil, 2017: The role of mid-level vortex in the intensification and weakening of tropical cyclones. J. Earth Syst. Sci., 126, 94, https://doi.org/10.1007/s12040-017-0879-y.

Leppert, K. D., and D. J. Cecil, 2016: Tropical cyclone diurnal cycle as observed by TRMM. Mon. Wea. Rev., 144, 2793-2808, https://doi.org/10.1175/MWR-D-15-0358.1. 
Melhauser, C., and F. Zhang, 2014: Diurnal radiation cycle impact on the pregenesis environment of Hurricane Karl (2010). J. Atmos. Sci., 71, 1241-1259, https://doi.org/10.1175/JAS-D13-0116.1.

Miller, R. A., and W. M. Frank, 1993: Radiative forcing of simulated tropical cloud clusters. Mon. Wea. Rev., 121, 482-498, https://doi.org/10.1175/1520-0493(1993)121<0482: RFOSTC $>2.0 . \mathrm{CO} ; 2$.

Montgomery, M., M. Nicholls, T. Cram, and A. Saunders, 2006: A vortical hot tower route to tropical cyclogenesis. J. Atmos. Sci., 63, 355-386, https://doi.org/10.1175/JAS3604.1.

Muller, C. J., and D. M. Romps, 2018: Acceleration of tropical cyclogenesis by self-aggregation feedbacks. Proc. Natl. Acad. Sci. USA, 115, 2930-2935, https://doi.org/10.1073/ pnas. 1719967115.

Navarro, E. L., and G. J. Hakim, 2016: Idealized numerical modeling of the diurnal cycle of tropical cyclones. J. Atmos. Sci., 73, 4189-4201, https://doi.org/10.1175/JAS-D-15-0349.1.

—_, — , and H. E. Willoughby, 2017: Balanced response of an axisymmetric tropical cyclone to periodic diurnal heating. J. Atmos. Sci., 74, 3325-3337, https://doi.org/10.1175/JASD-16-0279.1.

Nicholls, M. E., 2015: An investigation of how radiation may cause accelerated rates of tropical cyclogenesis and diurnal cycles of convective activity. Atmos. Chem. Phys., 15, 9003-9029, https://doi.org/10.5194/acp-15-9003-2015.

—_, and M. T. Montgomery, 2013: An examination of two pathways to tropical cyclogenesis occurring in idealized simulations with a cloud-resolving numerical model. Atmos. Chem. Phys., 13, 5999-6022, https://doi.org/10.5194/acp-135999-2013.

—_ R. A. Pielke Sr., D. Wheeler, G. Carrio, and W. P. Smith, 2018: A numerical modelling investigation of the role of diabatic heating and cooling in the development of a midlevel vortex prior to tropical cyclogenesis-Part 1: The response to stratiform components of diabatic forcing. Atmos. Chem. Phys., 18, 14 393-14 416, https://doi.org/10.5194/acp18-14393-2018.

Nolan, D. S., 2007: What is the trigger for tropical cyclogenesis? Aust. Meteor. Mag., 56, 241-266.

, and M. G. McGauley, 2012: Tropical cyclogenesis in wind shear: Climatological relationships and physical processes. Cyclones: Formation, Triggers, and Control, K. Oouchi and H. Fudeyasu, Eds., Nova Science, 1-36.

_ J J. A. Zhang, and D. P. Stern, 2009: Evaluation of planetary boundary layer parameterizations in tropical cyclones by comparison of in situ observations and high-resolution simulations of Hurricane Isabel (2003). Part I: Initialization, maximum winds, and the outer-core boundary layer. Mon. Wea. Rev., 137, 3651-3674, https://doi.org/10.1175/ 2009MWR2785.1.

Pielke, R. A., Jr., and R. A. Pielke Sr., 1997: Hurricanes: Their Nature and Impacts on Society. John Wiley and Sons, 279 pp.

Pielke, R. A., Sr., and Coauthors, 1992: A comprehensive meteorological modeling system-RAMS. Meteor. Atmos. Phys., 49, 69-91, https://doi.org/10.1007/BF01025401.

Ramsay, H. A., 2013: The effects of imposed stratospheric cooling on the maximum intensity of tropical cyclones in axisymmetric radiative-convective equilibrium. J. Climate, 26, 9977-9985, https://doi.org/10.1175/JCLI-D-13-00195.1.

Rappin, E. D., D. S. Nolan, and K. A. Emanuel, 2010: Thermodynamic control of tropical cyclogenesis in environments of radiative-convective equilibrium with shear.
Quart. J. Roy. Meteor. Soc., 136, 1954-1971, https:// doi.org/10.1002/qj.706.

Raymond, D., and C. López Carrillo, 2011: The vorticity budget of developing Typhoon Nuri (2008). Atmos. Chem. Phys., 11, 147-163, https://doi.org/10.5194/acp-11-147-2011.

Reasor, P. D., M. T. Montgomery, and L. F. Bosart, 2005: Mesoscale observations of the genesis of Hurricane Dolly (1996). J. Atmos. Sci., 62, 3151-3171, https://doi.org/10.1175/ JAS3540.1.

Ritchie, E. A., and G. J. Holland, 1997: Scale interactions during the formation of Typhoon Irving. Mon. Wea. Rev., 125, 1377-1396, https://doi.org/10.1175/1520-0493(1997)125<1377: $\mathrm{SIDTFO}>2.0 . \mathrm{CO} ; 2$.

Rotunno, R., and K. A. Emanuel, 1987: An air-sea interaction theory for tropical cyclones. Part II: Evolutionary study using a nonhydrostatic axisymmetric numerical model. J. Atmos. Sci., 44, 542-561, https://doi.org/10.1175/15200469(1987)044<0542:AAITFT>2.0.CO;2.

Schmetz, J., and M. Beniston, 1986: Relative effects of solar and infrared radiative forcing in a mesoscale model. Bound.-Layer Meteor., 34, 137-155, https://doi.org/10.1007/ BF00120913.

Skamarock, W. C., and Coauthors, 2008: A description of the Advanced Research WRF version 3. NCAR Tech. Note NCAR/TN-475+STR, 113 pp., https://doi.org/10.5065/D68S4MVH.

Tang, X., and F. Zhang, 2016: Impacts of the diurnal radiation cycle on the formation, intensity, and structure of Hurricane Edouard (2014). J. Atmos. Sci., 73, 2871-2892, https://doi.org/ 10.1175/JAS-D-15-0283.1.

— Z Z.-M. Tan, J. Fang, Y. Q. Sun, and F. Zhang, 2017: Impact of the diurnal radiation cycle on secondary eyewall formation. J. Atmos. Sci., 74, 3079-3098, https://doi.org/10.1175/JAS-D17-0020.1.

,,,--- E. B. Munsell, and F. Zhang, 2019: Impact of the diurnal radiation contrast on the contraction of radius of maximum wind during intensification of Hurricane Edouard (2014). J. Atmos. Sci., 76, 421-432, https://doi.org/10.1175/ JAS-D-18-0131.1.

Tao, W., S. Lang, J. Simpson, C. Sui, B. Ferrier, and M. Chou, 1996: Mechanisms of cloud-radiation interaction in the tropics and midlatitudes. J. Atmos. Sci., 53, 2624-2651, https://doi.org/ 10.1175/1520-0469(1996)053<2624:MOCRII >2.0.CO;2.

Thompson, G., P. R. Field, R. M. Rasmussen, and W. D. Hall, 2008: Explicit forecasts of winter precipitation using an improved bulk microphysics scheme. Part II: Implementation of a new snow parameterization. Mon. Wea. Rev., 136, 5095-5115, https://doi.org/10.1175/2008MWR2387.1.

Trabing, B. C., M. M. Bell, and B. R. Brown, 2019: Impacts of radiation and upper-tropospheric temperatures on tropical cyclone structure and intensity. J. Atmos. Sci., 76, 135-153, https://doi.org/10.1175/JAS-D-18-0165.1.

Van Sang, N., R. K. Smith, and M. T. Montgomery, 2008: Tropicalcyclone intensification and predictability in three dimensions. Quart. J. Roy. Meteor. Soc., 134, 563-582, https://doi.org/ 10.1002/QJ.235.

Wang, S., S. J. Camargo, A. H. Sobel, and L. M. Polvani, 2014: Impact of the tropopause temperature on the intensity of tropical cyclones: An idealized study using a mesoscale model. J. Atmos. Sci., 71, 4333-4348, https://doi.org/10.1175/JAS-D14-0029.1.

Wang, Z., 2012: Thermodynamic aspects of tropical cyclone formation. J. Atmos. Sci., 69, 2433-2451, https://doi.org/10.1175/ JAS-D-11-0298.1. 
Webster, P. J., and G. L. Stephens, 1980: Tropical uppertropospheric extended clouds: Inferences from Winter MONEX. J. Atmos. Sci., 37, 1521-1541, https://doi.org/ 10.1175/1520-0469-37.7.1521.

Wing, A. A., S. J. Camargo, and A. H. Sobel, 2016: Role of radiative-convective feedbacks in spontaneous tropical cyclogenesis in idealized numerical simulations. J. Atmos. Sci., 73, 2633-2642, https://doi.org/10.1175/JAS-D-15-0380.1.
Xu, K.-M., and D. A. Randall, 1995: Impact of interactive radiative transfer on the macroscopic behavior of cumulus ensembles. Part II: Mechanisms for cloud-radiation interactions. J. Atmos. Sci., 52, 800-817, https://doi.org/ 10.1175/1520-0469(1995)052<0800:IOIRTO > 2.0.CO;2.

Zehr, R. M., 1992: Tropical cyclogenesis in the western North Pacific. NOAA Tech. Rep. NESDIS 61, 181 pp., https:// repository.library.noaa.gov/view/NOAA/13116. 